\title{
ASPECTOS DAS POTENCIALIDADES DE USO PÚBLICO NO PARQUE ESTADUAL CUNHAMBEBE, MUNICÍPIO DE ANGRA DOS REIS-RJ
}

Anelise Rocha Assumpção ${ }^{1}$

Raquel Conceição Carvalho ${ }^{2}$

\section{RESUMO}

O Parque Estadual Cunhambebe (PEC) foi criado em 2008, abrangendo parte dos municípios de Angra dos Reis, Rio Claro, Mangaratiba e Itaguaí, com área total de 38.053 ha. O PEC é uma Unidade de Conservação de Proteção Integral, ou seja, é permitido apenas o uso indireto. A análise uso público no PEC no município de Angra dos Reis é o objeto deste estudo. Foram identificadas algumas potencialidades de uso público no PEC, em Angra dos Reis e realizado um mapeamento das principais vias de acesso ao parque no município e alguns dos principais pontos de interesse.

Palavras chave: Unidade de conservação; Pontos de Interesse; Mata Atlântica

\begin{abstract}
Cunhambebe State Park (PEC) was established in 2008, covering the municipalities of Angra dos Reis, Rio Claro, Mangaratiba and Itaguai, with total area of 38,053 ha. The PEC is an Integral Protection Conservation Unit, just is allowed the indirect use. The analysis of public use in the PEC in the city of Angra dos Reis is the object of this study. Some public use potentials have been identified in the PEC, in Angra dos Reis, the main access roads were mapped and the main points of interest.
\end{abstract}

Keywords: Conservation Unit; Points of interest; Atlantic Forest

\section{INTRODUÇÃO}

As Unidades de Conservação (UC) são espaços territoriais e seus recursos ambientais, incluindo as águas jurisdicionais, com características naturais relevantes, legalmente instituídas pelo Poder Público, com objetivos de conservação e limites definidos, sob regime especial de administração, ao qual se aplicam garantias adequadas de proteção (BRASIL, 2000).

Com o objetivo de assegurar a preservação dos remanescentes de Mata Atlântica da porção fluminense da Serra do Mar, bem como recuperar as áreas degradadas existentes, foi criado o

\footnotetext{
${ }^{1}$ Mestranda em Geografia na Universidade Federal Fluminense. E-mail: aneliserochaassumpcao@gmail.com

${ }^{2}$ Mestranda em Engenharia Cartográfica no Instituto Militar de Engenharia. E-mail: carvalho.raquelc@gmail.com
} 
Parque Estadual Cunhambebe (PEC) em 2008, abrangendo parte dos municípios de Angra dos Reis, Rio Claro, Mangaratiba e Itaguaí, com área total de 38.053 ha.

O PEC é uma UC de Proteção Integral, cujo objetivo básico é a preservação da natureza, sendo admitido apenas o uso indireto $^{3}$ dos seus recursos e ecossistemas naturais de grande relevância ecológica e beleza cênica, possibilitando a realização de pesquisas científicas e o desenvolvimento de atividades de educação, de interpretação ambiental, de recreação em contato com a natureza e de turismo ecológico. É o segundo maior parque estadual do Rio de Janeiro. No entanto, mesmo após 7 anos de sua criação, ainda não há sede própria.

No presente estudo abordou-se a área do PEC contida no município de Angra dos Reis, no qual ainda não foram implantadas estruturas administrativas (sede, sub sede ou núcleos) e nem de visitação (centro de visitantes, etc). O decreto estadual $n^{\circ} 42.483 / 10$ tem o objetivo de estabelecer diretrizes para o uso público nos parques estaduais administrados pelo Instituto Estadual do Ambiente - INEA, além de ordenar e controlar a visitação e uso público ${ }^{4}$, com visitação segura e de qualidade.

O PEC é um forte aliado ao desenvolvimento local sustentável no âmbito da gestão participativa. As relações da sociedade com a natureza devem valorizar os aspectos das fisionomias, arranjos estruturais e funcionalidades socioambientais (ROSS, 2009).

A fim de identificar algumas potencialidades de uso público no PEC, em Angra dos Reis, foi realizado um mapeamento das principais vias de acesso ao parque no município e os principais pontos de interesse.

\section{CONTEXTO AMBIENTAL DA ÁREA DE ESTUDO}

A área de estudo situa-se na região sudeste brasileira, no Estado do Rio de Janeiro, Município de Angra dos Reis.

O estado do Rio de Janeiro apresenta um relevo bastante acidentado com alinhamento sudoeste-nordeste, de maneira aproximada, sucedem-se em faixas estreitas os três componentes principais do quadro morfológico do estado: as baixadas, os maciços litorâneos e os planaltos.

A localização do PEC abrange parte dos municípios de Angra dos Reis, Rio Claro, Mangaratiba e Itaguaí, com uma área de 38.053 ha. Este parque está no domínio dos planaltos. (Figura 1).

\footnotetext{
3 Uso indireto: aquele que não envolve consumo, coleta, dano ou destruição dos recursos naturais.

${ }^{4}$ Visitação com finalidade recreativa, esportiva, turística, históricocultural, pedagógica, artística, científica e de interpretação e conscientização ambiental, que se utiliza dos atrativos dos parques estaduais e da infraestrutura e equipamentos eventualmente disponibilizados para tal.
} 


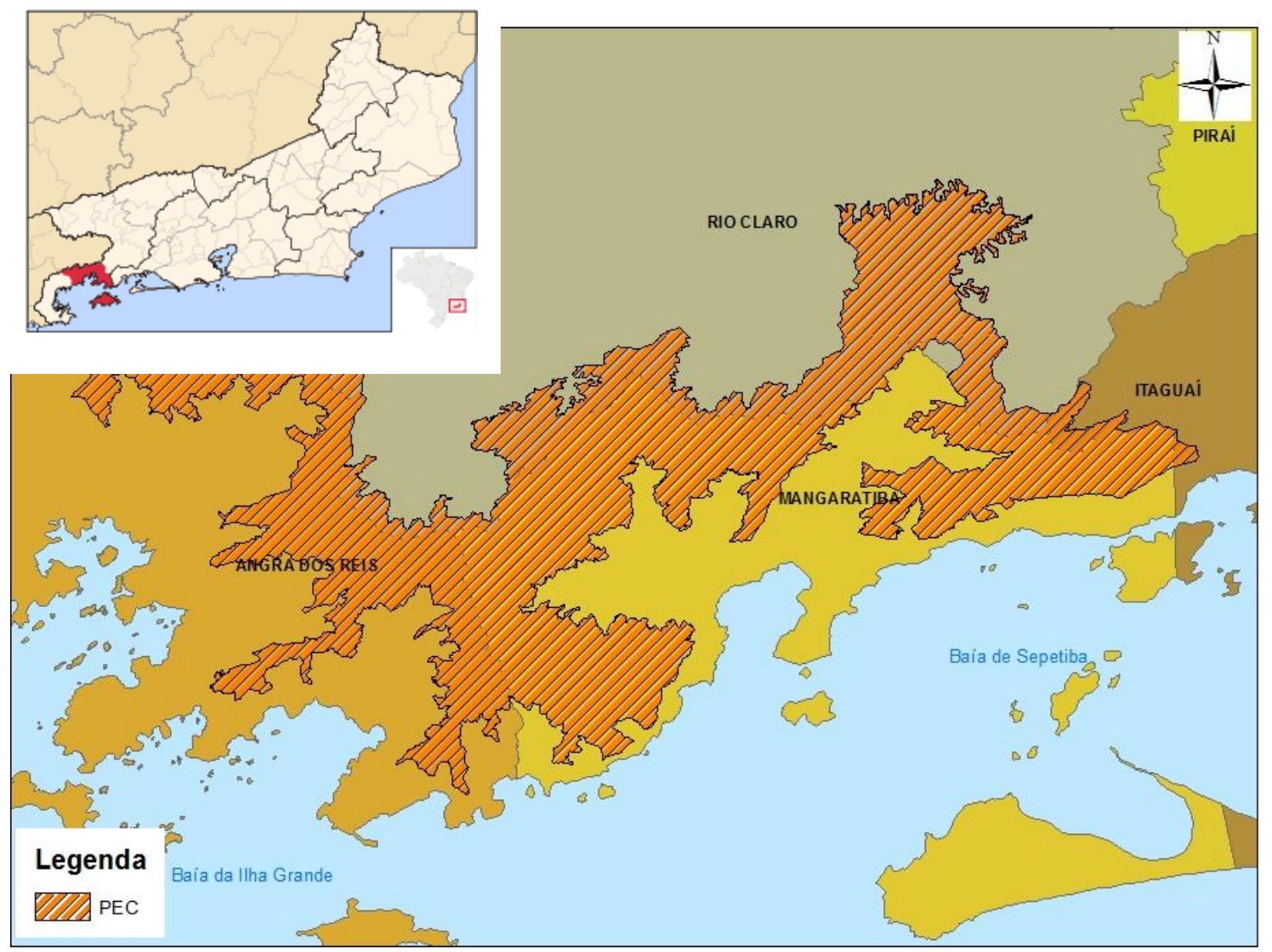

Figura 1. Mapa de localização do PEC. Mapa: Anelise Assumpção

O estado do Rio de Janeiro pode ser compartimentado em duas grandes unidades morfoestruturais: o Cinturão Orogênico do Atlântico e as Bacias Sedimentares Cenozóicas (DANTAS, 2001). A geomorfologia de Angra dos Reis faz parte do Cinturão Orogênico do Atlântico e está inserida no domínio morfoescultural das Escarpas Serranas, com o nome local de Serra do Mar. Caracteriza-se pela presença de um relevo muito acidentado e uma estreita planície costeira, resultado de um extenso recuo erosivo de antiga escarpa de falha originada junto à Falha de Santos, a partir do Paleoceno, segundo Almeida \& Carneiro (1998). As escarpas serranas apresentam, em geral, desnivelamentos extremamente elevados, por vezes, superiores a $2.000 \mathrm{~m}$ com vertentes muito íngremes e rochosas. As configurações morfológicas dos escarpamentos são bastante diversificadas, causadas principalmente por condicionantes litoestruturais. Assim sendo, pode-se observar tanto uma muralha montanhosa imponente, quanto um degrau escarpado mais degradado devido à ação diferencial dos processos tectônicos e erosivos durante todo o Cenozóico.

A Serra do Mar é, na maioria das vezes, a primeira a ser atingida pelas correntes perturbadas de origem subpolar. É mais pluviosa que a Serra da Mantiqueira e subtrai a umidade 
do ar para o Vale do Paraíba (DAVIS e NAGHETTINI, 2001). O maior número de precipitações está ligado às instabilidades frontais e pós-frontais. Este fator, conjugado ao deslocamento de frentes frias, promovem chuvas frequentes e intensas em Angra dos Reis.

Durante o verão há um número maior de horas de exposição ao sol, com elevação da temperatura e aumento da instabilidade, pois as chuvas, especialmente nesta estação do ano, são intensas e frequentes (NICOLLI, 1993; DAVIS \& NAGHETTINI, 2001). É também no verão que comumente ocorre a formação da Zona de Convergência do Atlântico Sul (ZCAS), que é um dos mais importantes fenômenos na escala intra-sazonal. A ZCAS está relacionada à conexão de frentes frias à umidade da região Amazônica. Este sistema meteorológico geralmente resulta em episódios excepcionais de precipitação, cujos valores podem superar $300 \mathrm{~mm} \mathrm{em} 24 \mathrm{~h}$ (SALGADO \& VASQUES, 2009).

Durante o inverno, o efeito das massas polares é preponderante. A influência da maritimidade e da extensa cobertura vegetal constituem fatores que são capazes de reduzir drasticamente a temperatura, principalmente durante a noite, quando a temperatura fica em torno de $15^{\circ} \mathrm{C}$. Nos meses de inverno, o sistema predominante é a massa de ar Tropical Atlântica, associada ao Anticiclone do Atlântico Sul (BRANDÃO, 1996). Este sistema caracteriza-se por uma forte estabilidade, impedindo a formação de nuvens e deixando a umidade relativa do ar baixa. Os totais pluviométricos também ficam bem reduzidos neste período, por consequência, os movimentos de massa também.

Os solos predominantes na região mais elevada da Serra do Mar são os das classes de Neossolos Litólicos e dos Cambissolos (IBGE, 2001). Uma das principais características destes é serem pouco profundos e, muitas vezes, cascalhentos. São solos jovens, facilmente intemperizados, que possuem minerais primários e altos teores de silte, até mesmo nos horizontes superficiais.

$\mathrm{Na}$ base das escarpas predominam solos das classes dos Latossolos que são solos profundos, bem drenados, homogêneos e muito intemperizados e lixiviados. Têm teores de argila médios ou altos. Este tipo de solo está presente em relevo de morros, morrotes e morros paralelos, sobre granito, xistos e gnaisses xistosos (OLIVEIRA et al, 1992). Na base das encostas, há também a presença dos Argissolos, que se caracterizam por apresentar gradiente textural entre horizontes superficiais (A, E, ou $\mathrm{A} / \mathrm{B}$ ) e subsuperficiais $(\mathrm{Bt}, \mathrm{B} / \mathrm{C})$, definido por um aumento acentuado no teor de argila em profundidade no solo. $\mathrm{O}$ gradiente textural pode condicionar caráter abrupto, de acordo com os critérios definidos pela EMBRAPA (1988). A presença de gradiente textural diminui a permeabilidade à água, resultando em drenagem moderada do solo e com efeito sobre a susceptibilidade à erosão, que é maior nestes solos em relação aos Latossolos (EMBRAPA, 1999; OLIVEIRA et al., 1992).

Já nas baixadas litorâneas e planícies fluviomarinhas predominam os hidromórficos das classes Neossolos Flúvicos que são formados por sedimentos aluviais (aluviões, cordões 
marinhos e praias, fluviomarinhos e mangues) de textura argilosa, média ou arenosa, sendo que os de textura média e arenosa apresentam boa permeabilidade. São solos profundos limitados pela presença do lençol freático.

A vegetação dominante no município é a Floresta Ombrófila Densa (IBAMA, 2000). Esta pode ser dividida em floresta ombrófila densa montana (desenvolvida em altitudes superiores a $500 \mathrm{~m}$ ), submontana (entre 50 e 500m) e Floresta de Terras Baixas (até 50m). Outros tipos de cobertura vegetal encontrados em Angra dos Reis são: restinga, ocupando solos arenosos de algumas praias, e mangue, recobrindo áreas litorâneas onde há baixa salinidade devido à desembocadura de rios.

\section{MATERIAIS E MÉTODOS}

A fim de analisar o uso público no PEC, no município de Angra dos Reis, esta pesquisa percorreu duas etapas: atividades de gabinete e de trabalhos de campo. Em gabinete foram desenvolvidas pesquisas bibliográficas, cartográficas, interpretação de dados e mapeamento. Esta etapa consistiu no levantamento de dados cartográficos, planos de informação e imagem de satélite. Foram utilizados os seguintes planos de informação: base cartográfica vetorial do IBGE (1:50.000) de municípios, limite do PEC disponibilizado pelo Instituto Estadual do Ambiente (INEA), além de imagem LANDSAT7, com composição de bandas RGB $(3,2,1)$. Os dados foram manipulados em ambiente GIS (ArcGis 10.2).

Nos trabalhos de campo, realizaram-se tarefas de interpretação da paisagem, de levantamentos de dados e documentação fotográfica. Foi feito um levantamento dos principais pontos de interesse no PEC em Angra dos Reis e o mapeamento dos principais atrativos turísticos, realizado através de um tracking (tracklog) com receptor GPS de alta sensibilidade.

\section{RESULTADOS}

O município de Angra dos Reis possui uma área de $825 \mathrm{~km}^{2}$. O PEC abrange uma área de $100 \mathrm{~km}^{2}$. Ou seja, $12,12 \%$ da área do município está protegida legalmente por esta unidade de conservação de proteção integral. A fim de identificar algumas potencialidades de uso público no PEC, em Angra dos Reis, foi realizado um mapeamento das principais vias de acesso ao parque no município. A BR-101 (trecho Rio-Santos) e a RJ-155 foram consideradas as principais (Figura 2). 


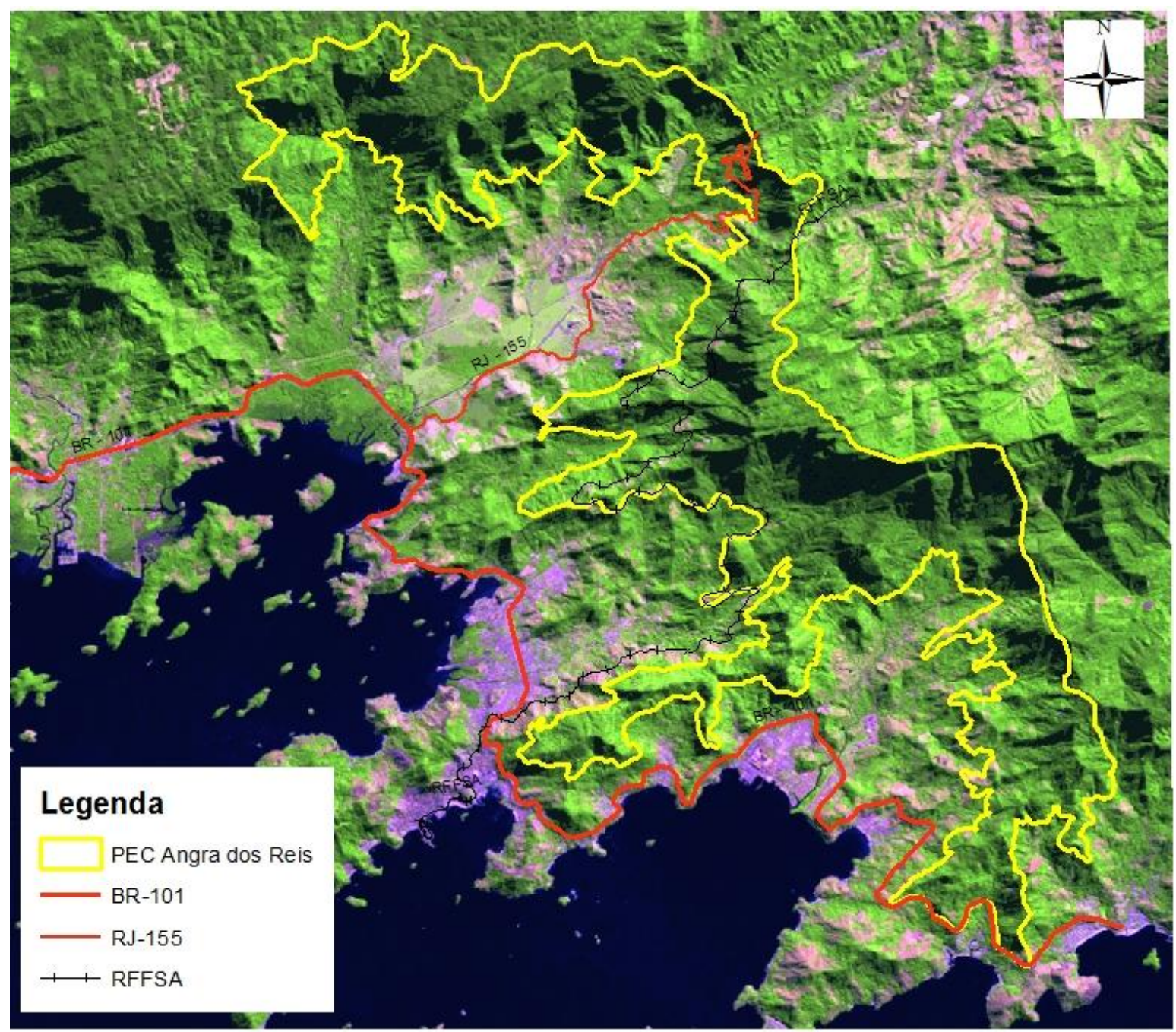

Figura 2. Principais vias no PEC em Angra dos Reis. Mapa: Anelise Assumpção

A BR-101 margeia o litoral e o PEC na porção oriental do município de Angra dos Reis. No entanto, através desta não é possível adentrar nos limites do parque. Já a RJ-155 corta longitudinalmente o PEC e inclusive faz a ligação com o município de Rio Claro através do distrito de Lídice.

A RJ-155 conecta a BR-101 (Rio-Santos)à BR-116 (Rodovia Presidente Dutra). É a principal via de acesso ao PEC em Angra dos Reis,. Nesta rodovia foram identificadas algumas potencialidades de usos públicos. Estes usos estão relacionados aos esportes de aventura, esportes radicais, turismo ecológico (ecoturismo) e lazer. Os as principais atividades são: ciclismo de estrada, mountain bike, trail run. 
Além de esportes radicais e turismo ecológico, esta área tem uma grande vocação para o turismo histórico, visto que parte da estrada imperial está dentro dos limites do parque, assim como a antiga Rede Ferroviária Federal (RFFSA).

O principal potencial turístico encontrado no PEC está ligado aos percursos em trilhas. Há uma travessia que acompanha a RFFSA, a qual liga Angra dos Reis ao distrito de Lídice-Rio Claro, denominada travessia Angra-Lídice. Nesta travessia existem as antigas estações da linha férrea, mirantes e cachoeiras.

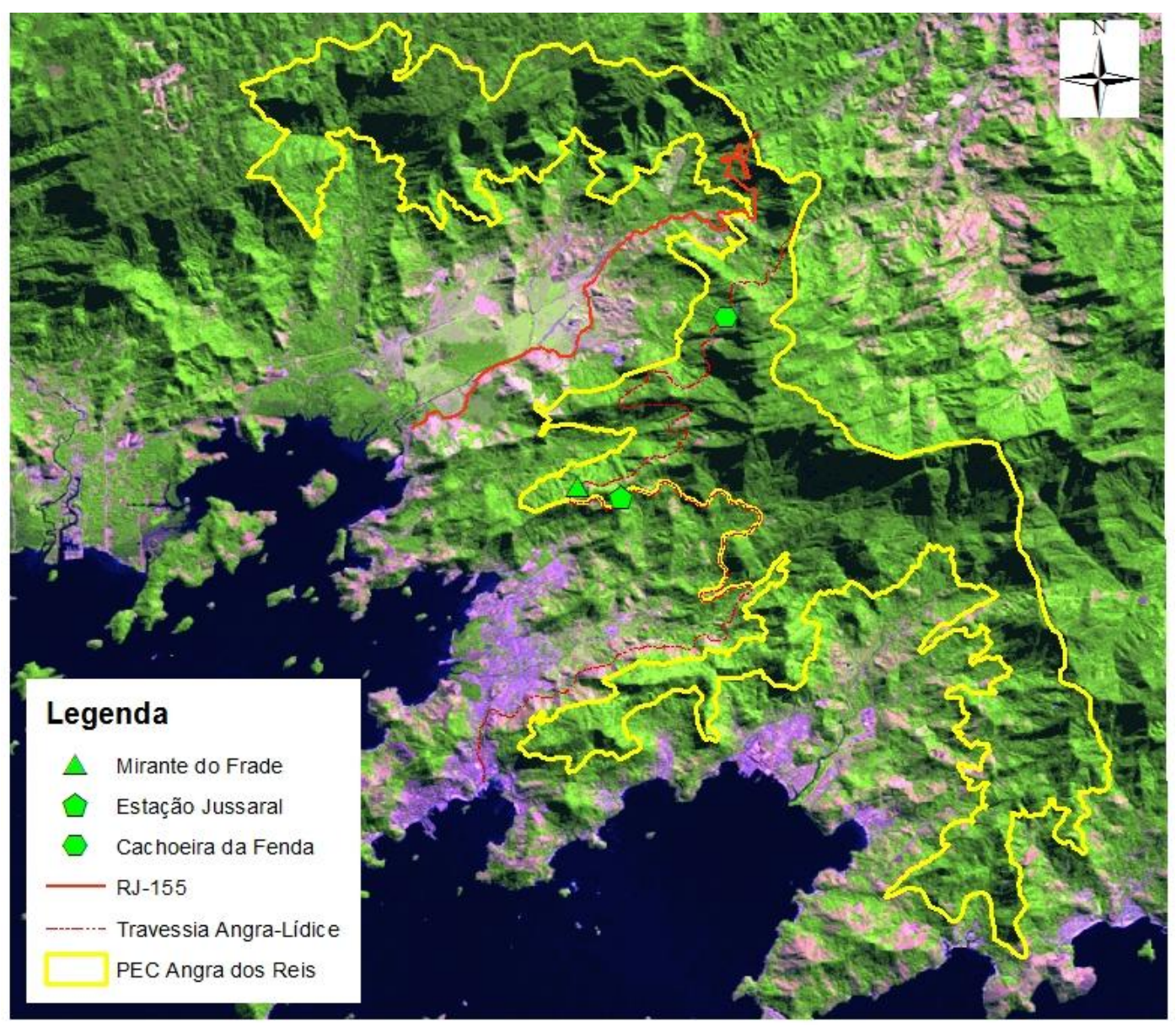

Figura 3. Mapa das principais pontos e vias de acesso do PEC. Mapa: Anelise Assumpção

Dentre todos os atrativos e possíveis usos públicos do PEC na trilha da travessia AngraLídice destacam-se as cachoeiras, dentre elas a Cachoeira da Fenda, a estação de Jussaral da RFFSA, inaugurada em 1925, e o Mirante do Frade (Figura 4). 

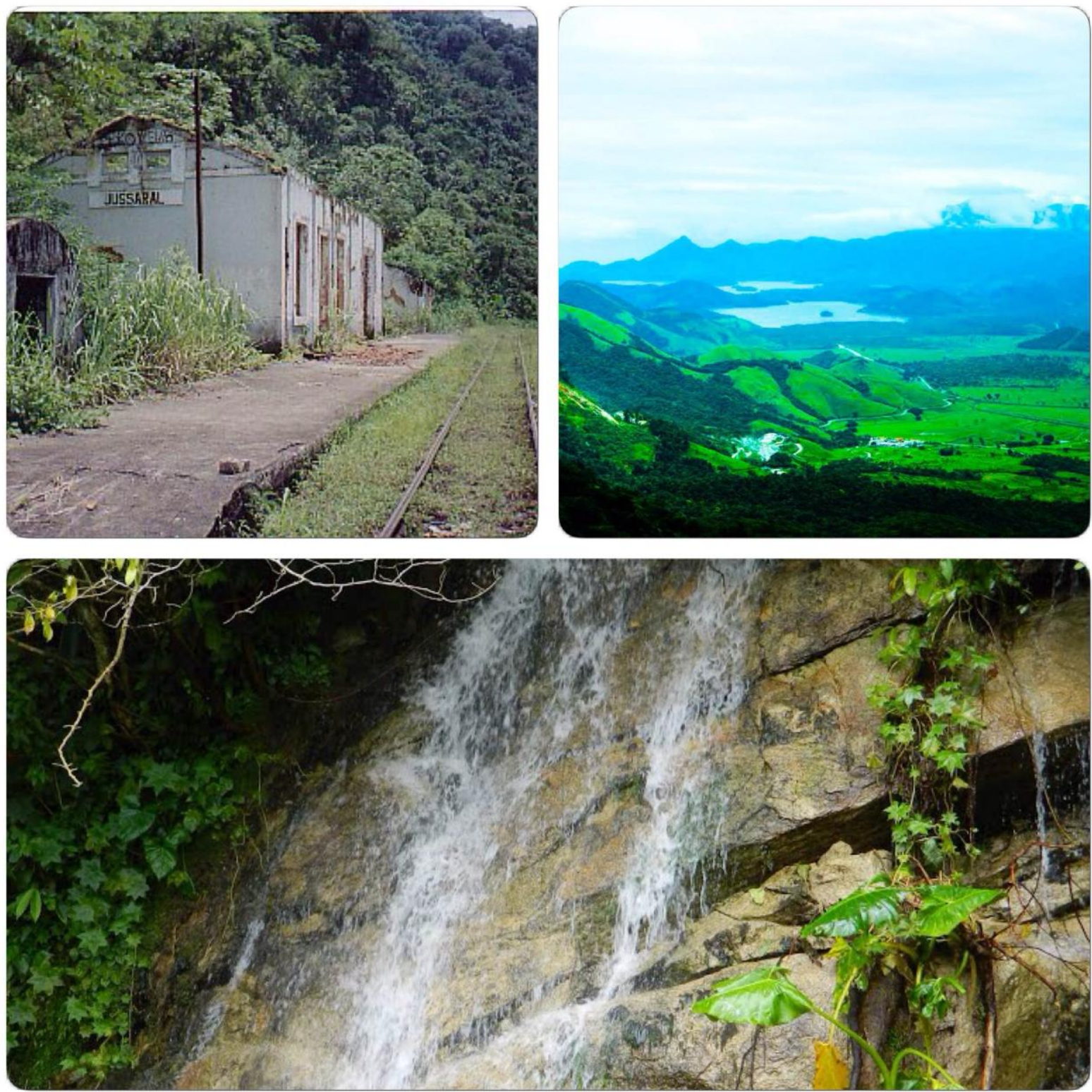

Figura 4. Esquerda superior: Estação de Jussaral (Foto: Décio Marques, 2012); direita superior: Mirante do Frade (Foto: Alexandre Souza, 2013); abaixo: Cachoeira da Fenda (Foto: Alexandre Souza, 2013). 


\section{CONCLUSÕES}

O PEC possui cobertura florestal em bom estado de conservação, abrigando um trecho de Mata Atlântica ainda pouco visitado e estudado. A potencialidade turística é muito grande, visto que o PEC possui muitos atrativos naturais e históricos. A sua floresta bem conservada representa uma importante peça do imenso mosaico de unidades de conservação que protegem a maior extensão contínua de Mata Atlântica no Corredor de Biodiversidade da Serra do Mar.

A práxis social desta área do PEC é uma importante via para o desenvolvimento local sustentável, visto que os parques são unidades de conservação de proteção integral que admitem a visitação com fins recreativos, constituindo um valioso instrumento de proteção ambiental através do desenvolvimento da consciência ecológica de seus praticantes.

A barreira física da Serra do Mar sempre foi um entrave na comunicação de Angra dos Reis com outros lugares. Desde a época colonial, a Serra do Mar contrastava desfavoravelmente com as excelentes condições oferecidas pela baía da Ilha Grande, o que estimulou o desenvolvimento das funções portuária e pesqueira, atividades que caracterizaram Angra dos Reis por quase quatrocentos anos.

Neste sentido, a área em que hoje constitui o PEC em Angra dos reis, não é um eixo do mercado turístico do município. Este mercado tem se apropriado da parte costeira e insular, mas não tem explorado o potencial turístico das montanhas de Angra dos Reis. Assim, conclui-se que esta área não está no processo de turistificação. Ou seja, não está circunscrita a um processo de planejamento que tem por objetivo convertê-las, material ou simbolicamente, em recursos e produtos substancialmente destinados ao consumo turístico (BENEVIDES, 2003).

Todas essas formas de consumo espaciais põem à prova a capacidade de suporte desses espaços no sentido estético-paisagístico, de acessibilidade e segregação, de resiliência e/ou susceptibilidade do ambiente, do papel simbólico exercido pela população e da limitação legal do uso e ocupação da terra. Portanto, os aspectos físicos e sociais devem ser analisados conjuntamente para que haja uma visão integrada da totalidade, desenvolvimento das atividades sociais conciliadas com as características funcionais do ambiente, é desta forma que as potencialidades devem ser exploradas. Logo, é imprescindível identificar os principais tipos de uso e as principais atividades envolvidas para nortear o uso público e adequá-los à capacidade de suporte do parque. 


\section{REFERÊNCIAS BIBLIOGRÁFICAS}

ALMEIDA, F. F. M., CARNEIRO, C. Dal Ré. Origem e evolução da Serra do Mar. Revista Brasileira de Geociências, 28, n. 2. p. 135-150, 1998.

BRASIL. Lei 9985 de 18 de julho de 2000. Institui o Sistema Nacional de Unidades de Conservação da Natureza, 2000.

BENEVIDES, I. P. O turismo e seu planejamento governamental no Ceará. In: Luzia Neide M. T. Coriolano (org). O Turismo de inclusão e o desenvolvimento local. Fortaleza: FUNECE, 2003.

DANTAS, M. E. Geomorfologia do Estado do Rio de Janeiro. In: CPRM-Serviço Geológico do Brasil. Estudo Geoambiental do Estado do Rio de Janeiro. Brasília, CPRM, 2001. Disponível em http://www.cprm.gov.br/arquivos/pdf/rj/geomorfologico/geomorfo_mpunid.pdf acesso em 19 de maio de 2015.

BRANDÃO, A. M. O Clima Urbano da Cidade do Rio de Janeiro. USP. Faculdade de Filosofia, Letras e Ciências Humanas. Departamento de Geografia. São Paulo, 1996. 362 p.

DAVIS, E. G. \& NAGHETTINI, M. C. Estudo de chuvas intensas no Estado do Rio de Janeiro. In: CPRM-Serviço Geológico do Brasil. Estudo Geoambiental do Estado do Rio de Janeiro. Brasília, CPRM, 2001. CD-Rom.

EMBRAPA. SNLCS. Critérios para distinção de classes de solos e de fases de unidades de mapeamento; normas em uso pelo SNLCS. Rio de Janeiro, 1988. $67 \mathrm{p}$

EMBRAPA. Sistema brasileiro de classificação de solos. Brasília: Serviço de Produção de Informações. 1999.

IBAMA INSTITUTO BRASILEIRO DO MEIO AMBIENTE E RECURSOS NATURAIS RENOVÁVEIS. Diretoria de Unidades de Conservação e Vida Silvestre. Parque Nacional da Serra da Bocaina: Plano de Manejo. Brasília: 2000.

IBGE. Mapa de Solos do Brasil. Rio de Janeiro, 2001. Escala 1:5.000.000.

NICOLLI, D. Períodos de precipitação intensa e a segurança da Central Nuclear em Angra dos Reis. In: SIMPÓSIO BRASILEIRO DE RECURSOS HÍDRICOS, 10., 1993, Gramado. Anais..., Gramado: ABRH, 1993.

OLIVEIRA, J. B.; JACOMINE, P. K. T.; CAMARGO, M. N. Classes gerais de solos do Brasil. 2.ed. Jaboticabal: FUNEP, 1992.

ROSS, J. L. S - Ecogeografia: subsídios para planejamento ambiental. São Paulo: Oficina de Textos 2009. 
RIO DE JANEIRO - Decreto $n^{\circ} 42.483$ de 27 de maio de 2010. Estabelece Diretrizes para o uso público nos parques estaduais administrados pelo Instituto Estadual do Ambiente INEA. 2010

SALGADO, C. M. \& VASQUEZ, N. D. Clima. In: O ambiente da Ilha Grande (M.P. Bastos \& C.H. Callado, eds.). Universidade do Estado do Rio de Janeiro, Rio de Janeiro, 2009. 